\title{
F-MARC: the FIFA Sudden Death Registry (FIFA-SDR)
}

Jürgen Scharhag, ${ }^{1}$ Philipp Bohm, ${ }^{1}$ Jiri Dvorak, ${ }^{2}$ Tim Meyer $^{1}$

\section{INTRODUCTION}

Death of an athlete during sports is tragic, and sudden cardiac death (SCD) is the most common cause. ${ }^{1-4}$ It is estimated, that the incidence of a SCD in athletes varies between 1:917000 and 1:3000, whereas studies with higher methodological quality consistently report ranges between $1: 40000$ to $1: 80000 .^{5}$ In addition, it has been stated that subgroups

\footnotetext{
${ }^{1}$ Institute for Sports and Preventive Medicine, Saarland University, Saarbrücken, Germany; ${ }^{2}$ FIFA Medical Assessment and Research Centre (F-MARC), Zurich, Switzerland

Correspondence to Dr Jürgen Scharhag, Institute for Sports and Preventive Medicine, Saarland University, Campus, Building B8.2, Saarbrücken 66123, Germany; juergen.scharhag@uni-saarland.de
}

and sport disciplines may be at a higher risk for SCD, such as males, AfricanAmericans, Africans/Americans, ${ }^{5}$ basketball, football and tennis. ${ }^{6}$

As football is the most popular sport in the world, with more than about 250 million active players registered, a relevant number of professional and recreational football players may have unknown cardiovascular diseases and therefore, be at risk for SCD. In an own nationwide registry on SCD in sports (Sudden Cardiac Death Germany; http://www.scd-deutschland.de), due to the high popularity of football and therefore, the high number of active and recreational football players in Germany, football was the most commonly affected sport discipline with 20 of the 73 cases (27\%) registered as SCD. ${ }^{7}$
Driven by the tragic SCD of the professional football player Marc Vivien Foe on the pitch during the FIFA Confederations Cup 2003, FIFA implemented a standardised 'precompetition medical assessment' (PCMA) in 2006 to detect cardiovascular pathologies and prevent SCD or sudden cardiac arrests (SCA; survived or successfully resuscitated cardiac death) in football players. Nevertheless, the optimisation of preventive sports medical screening programmes depends on the knowledge about the underlying diseases leading to sudden deaths as well as their regional, age and gender distribution, as the cardiovascular pathologies of SCD/SCA seem to differ between ethnicities with, for example, a higher proportion of hypertrophic cardiomyopathy in the $\mathrm{USA}^{2}$ versus a higher proportion of arrhythmogenic right ventricular cardiomyopathy in the Veneto region of Italy, ${ }^{8}$ Spain ${ }^{9}$ and Denmark, ${ }^{10}$ or myocardial infarction as the leading cause in other European countries. ${ }^{11-13}$

In a recent review, the percentage of football-related deaths among total sports- 


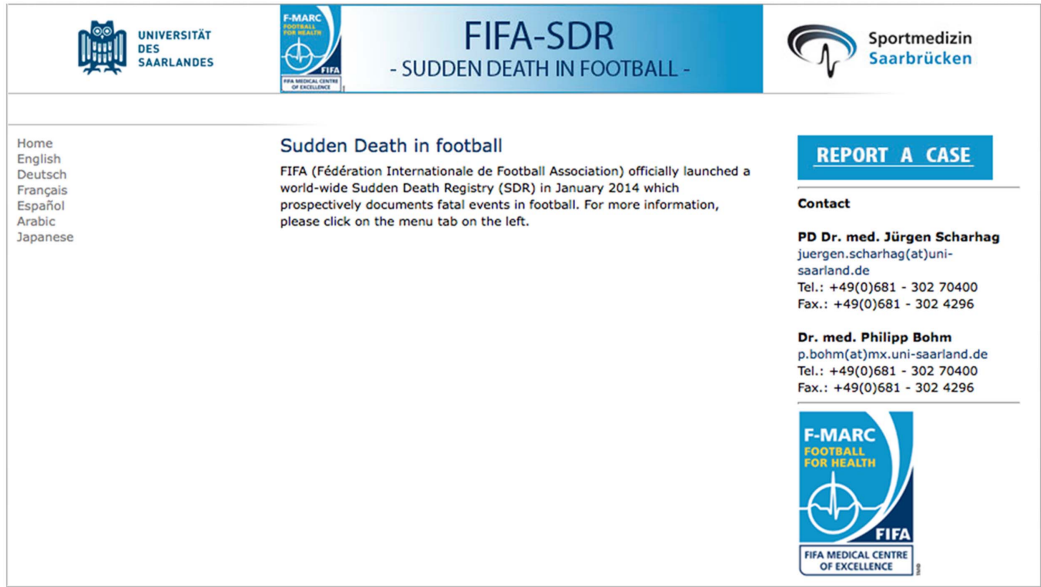

Figure 1 Starting internet-page of the FIFA Sudden Death Registry (FIFA-SDR) at http://www. sudden-death-in-football.com. By clicking the field 'REPORT A CASE' persons can report cases on a sudden death or successfully resuscitated sudden death of a football player via a confidential online access leading to the questionnaire.

related deaths differed considerably between various European countries and the USA, ranging from $4 \%$ to $100 \%(2 / 51$ to $15 / 15$ cases) football-related deaths. ${ }^{14}$ Furthermore, a retrospective survey covering the period from 2002 to 2012 reported

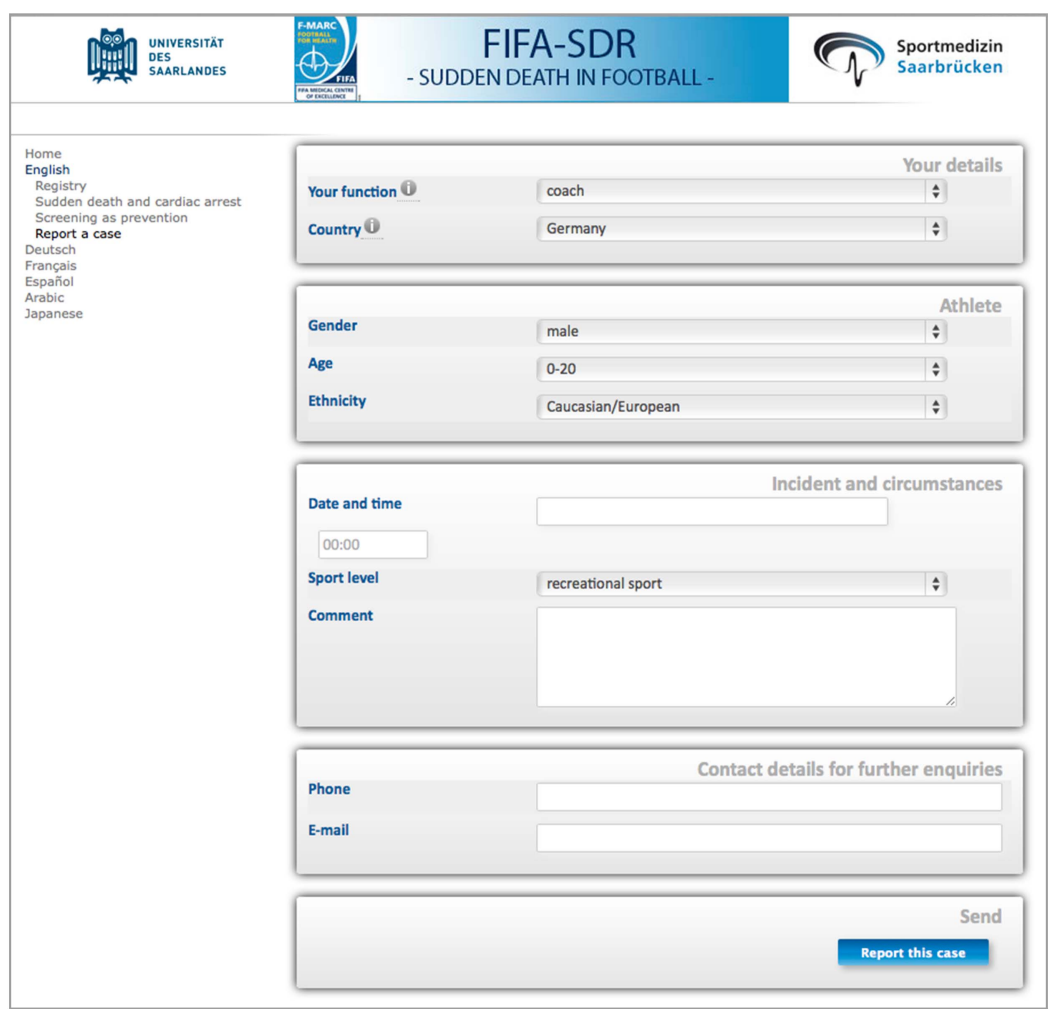

Figure 2 FIFA Sudden Death Registry (FIFA-SDR) case report questionnaire on the internet. Any involved person (eg, doctors, athletes, coaches, relatives, as well as others) can report a sudden death or successfully resuscitated sudden death of a football player and provide information on the circumstances. The personal data of deceased athletes, such as names or addresses, are not recorded. By clicking the boxes, 'Your function' and the 'Country' can be chosen. Furthermore, the gender, age category and ethnicity of the deceased athlete can be given. Further information on the incident and circumstances can be reported in 'Date and time', the 'Sporting level' ('recreational sport', 'competitive sport (no elite)' or 'competitive sport (elite)') and a field that allows further comments. Finally, the contact details for further enquiries should be given. By clicking 'Report the case', the information is sent to the Institute for Sports and Preventive Medicine, Germany, confidentially.
107 cases of SCD/SCA and 5 unexplained football-related sudden deaths in 126 of the 170 surveys returned from 209 FIFA member associations. In their article, the authors concluded that national registries which accurately measure SCD/SCA in football are rare and greatly needed. ${ }^{4}$ Therefore, in 2014 the Federation FIFA launched a Sudden Death Registry (FIFA-SDR) to document and examine fatal events in football worldwide.

\section{METHODS}

FIFA-SDR is built on an internet-based data platform, media-screening and national registries. The confidential internet-based data platform (http://www. sudden-death-in-football.com; figure 1) is under the auspices of FIFA and conducted by the Institute for Sports and Preventive Medicine in Saarbrücken, Germany, with a template to report cases from all over the world. The database records cases of sudden deaths as well as successfully resuscitated sudden deaths of football players occurring during or up to $1 \mathrm{~h}$ after football training or competition. FIFA-SDR database became operative in January 2014, starting with the four corresponding languages of FIFA (English, French, Spanish and German). Doctors, relatives, athletes, coaches and other persons involved can report cases via a confidential online access leading to a questionnaire regarding the circumstances of a sudden death or successfully resuscitated sudden death of a football player (figure 2). The personal data of deceased athletes, such as names or addresses, are not recorded.

In addition to the internet-based platform, existing national registries have been and will be contacted. Furthermore, a sample of countries will be chosen to representatively assess incidence and disease distribution in all continents, including monitoring of regional and nationwide media, wherever possible.

After initiation of the FIFA-SDR, the project was demonstrated to the public at the Team Physician Workshop for the FIFA World Cup 2014 (Florianopolis, Brazil). Furthermore, FIFA Medical Centres of Excellence were informed during a FIFA ad hoc session at the Isokinetic Conference 2014 (Milano, Italy). In addition, FIFA-SDR was presented to the members of the Working Group on Sports Cardiology of the European Society of Cardiology at the conference of the European Association for Cardiovascular Prevention and Rehabilitation (EACPR) in 2014 (Amsterdam, the Netherlands). Via email correspondence, the project was introduced to all 209 FIFA member 
associations and a short questionnaire was added to analyse the football-associated medical structures in the countries of the FIFA member associations.

The questionnaire sent to all FIFA member associations consisted of the following questions: (1) Does your national football association have a medical committee? (2) Does a national registry for incidents of sudden death, whether in sport in general, football or otherwise, exist in your country? (3) Is anyone in your country or at your national football association responsible for scouring the media for incidents of sudden death in sport in general or in football? (4) Is a cardiovascular PCMA performed for your football players before the start of the season? So far, 38 FIFA member associations replied. Of those, $30 \quad(79 \%)$ reported having a medical commission, 13 (34\%) reported having a national registry for sudden deaths and $14(37 \%)$ stated having media screening. A PCMA was reported to be performed in 35 (92\%) FIFA member associations.

\section{SUDDEN DEATHS}

By now, 23 cases of sudden deaths in football players have been registered. The mean age of the 22 male players and 1 female player was $27 \pm 11$ years. Twenty players died because of a SCD, while three suffered from a lethal traumatic injury. Fifteen deaths happened during the match, two during the warm-up, one after the match and five during training. Four sudden cardiac arrests could be resuscitated (2 myocardial infarctions, 1 coronary anomaly, 1 unknown underlying disease). Compared with the German Sudden Cardiac Death Registry (SCD-Deutschland; http://www.scd-deutschland.de) the international cases of sudden deaths during football were younger ( $22 \pm 5$ vs $35 \pm 15$ years).

\section{PERSPECTIVES}

For the first time, FIFA-SDR offers the opportunity to examine SCD and SCA in football players and therefore, to improve our knowledge and understanding of sudden deaths in apparently healthy athletes. Thereby, this data will help to detect possible regional or national differences, and to improve preventive measures which may be adapted to specific regional or national circumstances and conditions to further help prevent SCD/SCA in athletes.

Persons or associations who are interested in the FIFA-SDR and would like to cooperate are warmly welcome to contact FIFA-SDR by sportscardiology@unisaarland.de.

Competing interests None.

Ethics approval Ethics Committee of Saarland, Germany.

Provenance and peer review Not commissioned; internally peer reviewed.

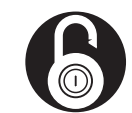

\section{OPEN ACCESS}

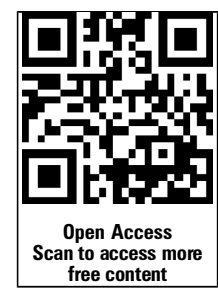

Open Access This is an Open Access article distributed in accordance with the Creative Commons Attribution Non Commercial (CC BY-NC 4.0) license, which permits others to distribute, remix, adapt, build upon this work non-commercially, and license their derivative works on different terms, provided the original work is properly cited and the use is noncommercial. See: http://creativecommons.org/licenses/ by-nc/4.0/

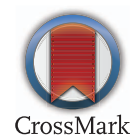

To cite Scharhag J, Bohm P, Dvorak J, et al. Br J Sports Med 2015;49:563-565.
Accepted 2 March 2015

Br J Sports Med 2015;49:563-565.

doi:10.1136/bjsports-2015-094770

\section{REFERENCES}

1 Maron BJ. Sudden death in young athletes. $N$ Engl J Med 2003:349:1064-75.

2 Maron BJ, Haas TS, Murphy CJ, et al. Incidence and causes of sudden death in U.S. college athletes. J Am Coll Cardiol 2014;63:1636-43.

3 Corrado D, Basso C, Rizzoli G, et al. Does sports activity enhance the risk of sudden death in adolescents and young adults? I Am Coll Cardiol 2003;42:1959-63.

4 Schmied C, Drezner J, Kramer E, et al. Cardiac events in football and strategies for first-responder treatment on the field. Br J Sports Med 2013;47: 1175-8.

5 Harmon KG, Drezner JA, Wilson MG, et al. Incidence of sudden cardiac death in athletes: a state-of-the-art review. Br J Sports Med 2014;48: 1185-92.

6 Link MS, Estes NAM. Sudden cardiac death in the athlete: bridging the gaps between evidence, policy, and practice. Circulation 2012;125: 2511-16.

7 Bohm P, Meyer T. Sports related sudden death in Germany: preliminary data from a nation-wide registry. Euro Prevent 2014:P714.

8 Corrado D, Schmied C, Basso C, et al. Risk of sports: do we need a pre-participation screening for competitive and leisure athletes? Eur Heart J 2011;32:934-44.

9 Suárez-Mier MP, Aguilera B. Causes of sudden death during sports activities in Spain. Rev Esp Cardiol 2002;55:347-58.

10 Holst AG, Winkel BG, Theilade J, et al. Incidence and etiology of sports-related sudden cardiac death in Denmark-implications for preparticipation screening. Heart Rhythm 2010;7: 1365-71.

11 Solberg EE, Gjertsen F, Haugstad E, et al. Sudden death in sports among young adults in Norway. Eur J Cardiovasc Prev Rehab 2010;17: 337-41.

12 Quigley F. A survey of the causes of sudden death in sport in the Republic of Ireland. Br J Sports Med 2000;34:258-61.

13 Marijon E, Tafflet M, Celermajer DS, et al. Sports-related sudden death in the general population. Circulation 2011;124:672-81.

14 Bohm P, Kästner A, Meyer T. Sudden cardiac death in football. J Sports Sci 2013;31: 1451-9. 